Open Access

\title{
Beyond fusion towards loT by way of open innovation: an investigation based on the Japanese machine tool industry 1975-2015
}

\author{
Fumio Kodama ${ }^{1 *}$ and Tomoatsu Shibata ${ }^{2}$
}

\author{
* Correspondence: \\ kodama_5@ga2.so-net.ne.jp \\ ${ }^{1}$ University of Tokyo, Tokyo, Japan \\ Full list of author information is \\ available at the end of the article
}

\begin{abstract}
In a last few decades, innovation research scholars proposed several new concepts, one after another, but independently, and in a chronological sequence: technology fusion; digital convergence; disruptive technology; open innovation; and loT (Internet of Things). Each concept has its own explaining power for a certain innovation at a certain time period, but has obvious limitations. A basic question is, therefore, whether each of those proposed concepts is independent among them or inter-related dynamically, i.e. in what sequences? In order to answer this question, a specific industrial product, i.e. machine tools, is selected for our study. Although the machine tool is described as the mother machine, i.e. the machine of all the machinery, this industry experienced a drastic technological shift toward NC (numerically controlled) revolution around 1975. However, up until now, this industry continues to be a pivotal industry in modern and high-tech industrial era. By reviewing the technological history of the Japanese machine tool industry from 1975 to 2015, we observed several technological shifts even after the $\mathrm{NC}$ revolution, each of which can be explained with one of those concepts proposed in the last decades. We find a dynamic interrelationship among those concepts in the following sequence with the publication dates in parenthesis: disruptive technology (1997), technology fusion (1992), open innovation (2003), digital convergence (1996). We describe characteristics and analytical framework for loT innovation that has gone beyond the traditional Schumpeterian formulation of innovation.
\end{abstract}

\section{Introduction}

On the eve of this century, Newsweek magazine (1999/7/21) published an article entitled "Convergence: Embracing a Next Millennium of Change". The article begins with a quote from a then executive vice-president of Lucent Technologies: "instead of administering and maintaining three different systems - one for phone, one for television and another for computer data - you have a single digital system, and maintenance costs can go way down. But besides cost, when you have a single converged system, you can start delivering multimedia services no one ever heard of before".

In just two decades before the end of the last millennium, digital technology has indeed reached a critical mass. But the digital revolution is more than just a revolution of expedience. The term that has come to encompass this revolution is "convergence", the fruit of the digital union of telecommunications, information technology, the Internet, and consumer electronics. In this article, one of the authors was asked to analyze

(c) The Author(s). 2017 Open Access This article is distributed under the terms of the Creative Commons Attribution 4.0 International License (http://creativecommons.org/licenses/by/4.0/), which permits unrestricted use, distribution, and reproduction in any medium, provided you give appropriate credit to the original author(s) and the source, provide a link to the Creative Commons license, and indicate if changes were made. 
the importance of convergence: I say fusion, you say convergence, but both mean essentially that the resulting products are greater than the sum of their parts—or, as commonly said $1+1$ makes 3 . In the analog world, one cannot combine things easily. With digitization, we can make every conceivable combination, and end up with something much greater than just a simple merger. Based on the Webster dictionary, and also by Yoffie (1996), convergence is defined as the unification of functions-the coming together of previously distinct products which employ digital technologies.

In the Newsweek article mentioned above, however, John Taylor, U.K.'s Office of Science and Technology queried: "Convergence? It Means Turbulence": TV companies think they know. PC companies think they know. The Internet companies think they know. But no one really does." More recently, in a different context, Steve Jobs (Cupertino Silicon Valley press, 2011) was quoted as saying: "We do not think that televisions and personal computers are going to merge. We think basically you watch television to turn your brain off and you work on your computer when you want to turn your brain on. All these statements indicate that convergence could not be taken for granted, and that we still have a long way to go before substantial realization of the convergence revolution. In short, our analysis of convergence turned out to be not so straightforward.

In order to better appreciate the full understanding of convergence, we need to take a long-term historical perspective on technology development (Kodama (2017); Lee (2017)). First of all, we find that convergence is not a direct outcome or consequence of digital technology. Rosenberg (1976) argued that nineteenth century industrialization was characterized by the introduction of a relatively small number of similar productive processes to a large number of industries. The use of machinery in cutting metal into precise shapes, for example, involves a relatively small number of operations such as turning, boring, drilling, milling, planing, grinding, and polishing. The machines encountered similar technical problems: power transmission, control devices, feed mechanisms, friction reduction, etc. Because these processes and problems were common to the production of a wide range of disparate commodities, industries such as firearms, sewing machines, and bicycles, became very closely related (technologically convergent) on a technological basis.

Rosenberg further argued that the machine tool industry, as a result of technological convergence, played a unique role both in the initial solution of technological problems and in the rapid transmission and application of newly-learned techniques in a machinofacture type of economy. Its main importance, therefore, lay in its strategic role in the learning process associated with industrialization. This role is a dual one: (1) new skills and techniques were developed or perfected in response to the demands of specific customers and; (2) once they were acquired, the machine tool industry was the main transmission center for the transfer of new skills and techniques to the entire machine-dependent sector of the economy.

Based on this context, we have studied the development of the NC (numerically-controlled) machine tools industry in Japan during the period from 1975 to 2015, i.e. the period during which the transformation of the machine tools industry using digital technologies was realized. Based on our research, we will demonstrate here that technology fusion and convergence are not isolated phenomena, but are inter-related in a dynamic and organic manner. Moreover, we will demonstrate the following transformational sequences occurred in machine tool technological development, with the 
publication dates in parenthesis: disruptive technology (1997), technology fusion (1992), open innovation (2003) and, digital convergence (1996). We will argue with reason why this sequence differs from the chronological sequence of publications.

All of these technological sequences/concepts are now convalescing into the so-called IoT (Internet-of-Things) revolution. In this context, we will give some thoughts on what essentially characterizes the IoT, and will discuss these characteristics in a framework that is different from that of Schumpeterian perspectives.

\section{Disruptive innovation}

In 1975, the Japanese created a new word, mechatronics, by combining the words mechanics and electronics. Essentially, mechatronics is the marriage of electronic technology to mechanical technology. From this union came a more sophisticated range of technological products, such as numerically controlled (NC) machine tools and industrial robots, as well as a series of products in which a part, or the whole, of a standard mechanical product was superseded by electronics, such as digital clocks and electronic calculators.

The mechatronics revolution, in particular, has transformed the machine tool industry. Two inventions crucial to the machine tool industry - an improved servo motor and a compact, simple to use, and cheap to make numerical controller - are the result of Japanese innovativeness. Until these inventions were made, a huge market segment of mid-sized and small industrial customers was neglected because the NC was too costly and too large for them. The origin of NC machine tools with unprecedented levels of precision and reliability, meanwhile, goes back to the late 1940s to U.S. institutions such as Massachusetts Institute of Technology (MIT). They invented the numerical controller for the milling machine in 1952. The device, however, had 2000 vacuum tubes, and its size was the size of a small room. While it controlled a machine tool automatically, it was huge and expensive, putting it out of reach of all but the largest industries, such as aircraft manufacturers. The numerical controller developed by MIT in the 1950s needed a large computer capable of sophisticated calculations.

Having discovered a possible lucrative niche in mid-sized and small industrial customers, Fanuc, a spin-off from Fujitsu which is a supplier of communication equipment, set out to develop a controller that was cheaper, simpler, and more compact than those of the current generation. This is exactly the strategy which Christensen (1997) described in terms of disruptive innovation, as is figuratively illustrated in Fig. 1.

They designed a new type of servo motor, called an electro-hydraulic (EH) stepping motor, in which electrical control pulses are converted into mechanical movements known as steps. The motor removed many operational complexities and, in particular, eliminated the need for a feedback loop, since the operation of EH motor is based on the open-loop principle. To complete the system, Fanuc returned to its need for a controller. Fanuc's controller was based on the scientific fact that it is possible to reduce most technical drawings to arcs (which can be expressed as a radius with starting and ending points) and straight lines (which can be defined as two points). Using this knowledge, Fanuc developed a machine that translates arcs and lines into pulses. The machine could be made smaller because of the switch from vacuum tubes to solid-state electronics. 


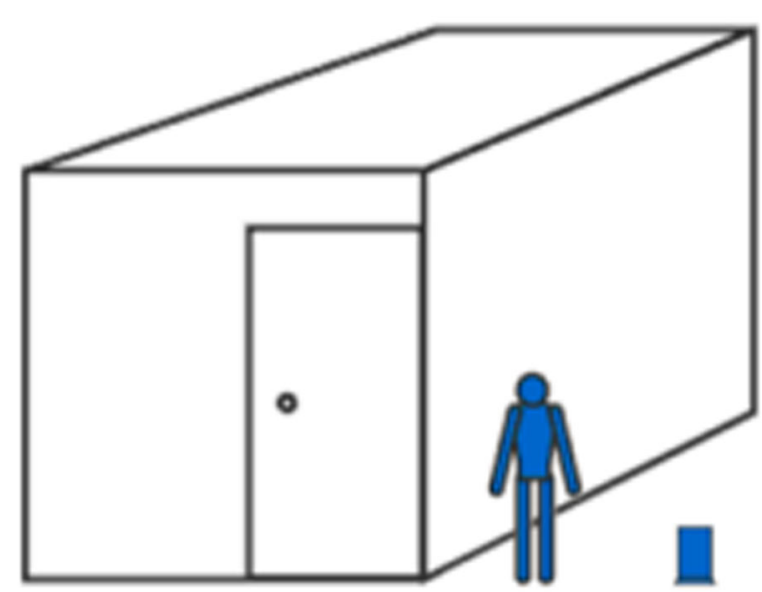

Fig. 1 Figurative illustration comparing Fanuc's NC system to the US system. A size of a small room is reduced to a mounting on the worktable

As a result, from 1975 to 1985, Japan's production of machine tools rose from fourth after the USSR to the top position in the world (see Fig. 2). Such growth in the world market in so short a time would not have been possible without substantial innovation in the industry, primarily due to mechatronics.

Indeed, this phenomena of leapfrogging cannot be explained only by technological disruption, but also by the new-market disruption to accommodate the unfulfilled needs of small- and medium-sized companies that had been neglected by the expensive NC machine tool providers of the United States. Christensen (2003) phrased this situation by the idea of nonconsumption. He argued:

A new-market disruption is an innovation that enables a larger population of people who previously lacked the money or skill now to begin buying and using a product and doing the job for themselves. From this point onward, we will use the terms nonconsumers and nonconsumption to refer to this type of situation, where the job needs to get done but a good solution historically has been beyond reach. We sometimes say that innovators who target these new markets are competing against nonconsumption.

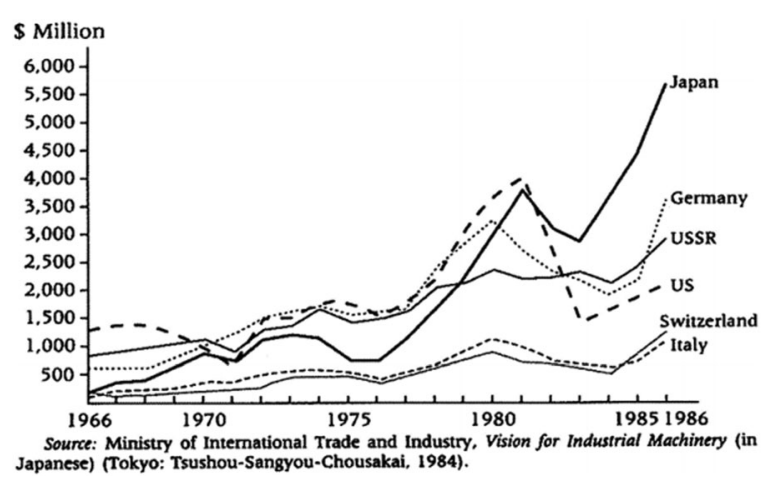

Fig. 2 Production of machine tools in major economies (1966-1986) 


\section{Technology fusion}

The device that harnesses the EH stepping motor to the worktable in a NC machine tool is called a ball screw. The ball screw was developed by Nippon Seiko Co. (NSK), Japan's leading maker of bearings. The ball screw's great advantage over its predecessor, the friction screw, lies in the lubricated ball bearings inserted between the screw's nut and bolt, which lessen friction. Consequently, the screw's mechanical characteristics do not change during its life. Without the development of a ball screw with perfect pitch then, it would not have been possible to hook up Fanuc's EH servo motor in an openloop control system.

A further contribution came from material suppliers such as Daikin Co. A coating of Teflon on the sliding bed of the machine tool enabled the hook up of the servo motor, which is good for precise adjustment but weak in torque. This also made low speed but uniform movement possible, a necessity for the operation of a machine tool. Through the development process described above, we can assert that Fanuc's NC system was realized by fusing three technologies developed in different industries into one, as can be seen in the two photos of Fig. 3.

The idea of "technology fusion" was proposed in order to characterize the thenemerging technologies such as mechatronics and optoelectronics (Kodama, 1986a, 1986b). And this conceptualization was identified as a unique Japanese capability to innovate (Kodama, 1992a). Indeed, the innovation pattern was shifting from technical breakthrough to technology fusion, and the management implications of this shift were also discussed (Kodama, 1992b, Lee, G., 2008, Lee, K., 2017). It was argued that the difference between success and failure is not how much a company spends on research and development but how it defines it. There are two possible definitions. Either a company can invest in R\&D that replaces an older generation of technology - the "breakthrough" approach - or it can focus on combining existing technologies into hybrid technologies-the "technology fusion" approach. The former is a linear, step-by-step strategy of substitution. Technology fusion, on the other hand, is nonlinear, complementary, and cooperative. It blends incremental technical improvements from several previously separate fields of technology to create products that revolutionize markets.

In terms of the sequencing problem, however, we can learn why the concept of the disruptive innovation (Christensen and Rosenbloom, 1995) preceded that of technology fusion (Kodama, 1986b) as far as the machine tool industry is concerned. Only after we had disruptive innovations in component technologies such as EH stepping motor and

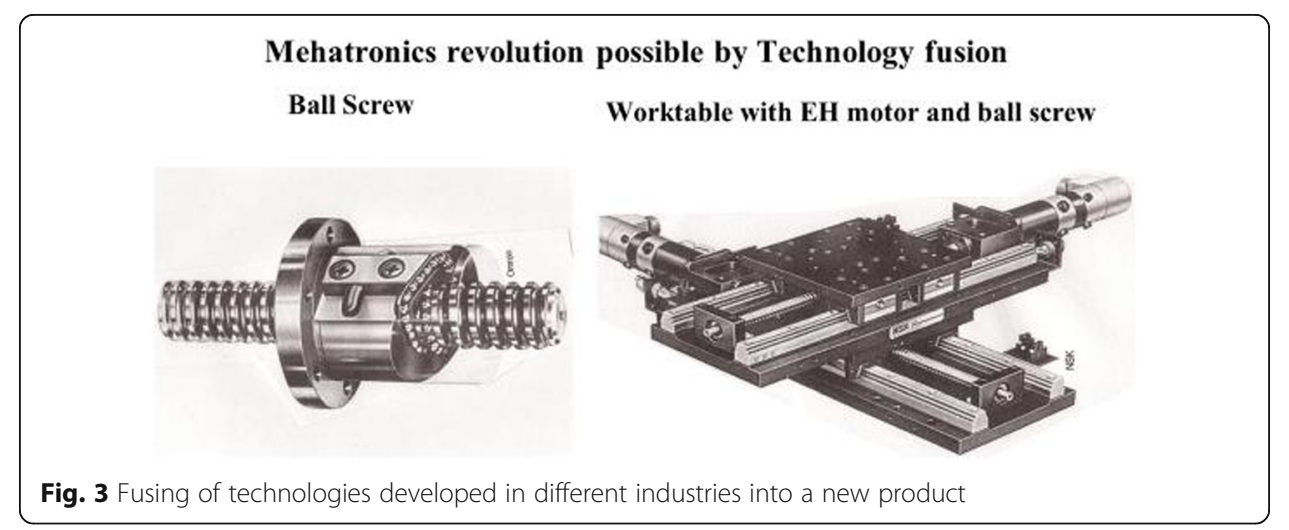


small numerical controller, could we attain the fusing of technologies in different sectors such as electronics, mechanical, and materials industries into a machine tool.

As described above, we discussed that the technology fusion approach focuses on combining existing technologies into hybrid technologies. This description, however, is not quite right in the sense that technology fusion cannot be realized without preceding disruptive innovations at the level of component technologies. In other words, technology fusion is not effective with available component technologies only. To be effective, we need to have disruptive component innovations. The existence of disruptive innovations is a necessary condition for technology fusion to be realized. Only by the realization of technology fusion, can the market need be met and the demand for disruptive component technologies articulated and pulled into the market (Kodama and Shibata, 2015).

This ordering and sequence between disruptive innovation and technology fusion, might not be so surprising indeed, if one considers the following prototypical example of disruptive innovation by a Japanese company compiled by Christensen (2003): the venerable RCA (Radio Corporation of America) was vaporized by Sony's "transistorized portable radio" in 1955.

\section{Open innovation}

Having brought disruptive technologies into the machine tool industry in the early 1970s, the Japanese machine tool industry was able to attain and maintain its number one position until 2015, as will be explained later in this paper. How did the Japanese industry sustain the momentum of innovation, or at least could survive for more than a quarter century since 1983 ?

After Fanuc made major innovations as described above, they had to confront the major shifts both in economic and in technological landscape. In other words, Fanuc had to undergo two major transitions (Shibata and Kodama, 2008). In these transitions, the company was faced with the dilemma of either switching to a new technology or sticking with the tried-and-true old technology. The first transition involved servomotor architecture, a key NC technology, entailing a major change from an open-loop architecture to a closedloop architecture. The second technology shift involved the NC logic unit architecture from hard-wired NC logic to a soft-wired NC logic based on MPU (micro-processor unit). How did Fanuc overcome these two transitions successfully?

In a celebrated work on "open innovation" by Chesbrough (2003), he argued: there are two sides to the Open Innovation Model. One side is "outside-in," bringing in external ideas and technologies into the innovation process. The other side is "insideout," enabling unused internal ideas and projects to go outside for others to use instead. The way in which Fanuc did overcome each of these two transitions, indeed, would provide us with a rich illustration both of the outside-in (inbound) and of the inside-out (outbound) innovation models. In fact, Fanuc overcame the first transition by following the inbound model of the open innovation. And the second transition followed the outbound model of open innovation. This was because the MPU technology which Intel developed in close collaboration with Fanuc was successfully transferred to the PC (personal computer) industry throughout the world. 


\section{Outside-in (inbound) model}

Fanuc Ltd. was established as a subsidiary start-up business by Fujitsu in 1956. Fanuc was then spun off as an independent company from Fujitsu in 1972, just in time to be challenged by the first oil crisis in the fall of 1973. This oil crisis caused users to start turning away from the electro-hydraulic $(\mathrm{EH})$ pulse motor, a technology by which Fanuc enjoyed an overwhelming competitive advantage. The EH pulse motor is an open-loop control servomotor with significant advantages in versatility and flexibility, and Fanuc had an unassailable position in this technology as holder of the patent rights. However, the EH pulse motor used a lot of oil.

The oil crisis of 1973 thus made users extremely uneasy about continuing to use the $\mathrm{EH}$ pulse motor in the future, as it pushed up the price of oil to unprecedented levels. At that time there were two basic motor technology options available: a pulse motor with open-loop control, and a DC servomotor with closed-loop control. The first task was to explore technological limits of an electric pulse motor with the same architecture as the EH pulse motor. The second task was to scrutinize the work of the USbased DC servomotor manufacturer, Gettys Manufacturing Company Inc. to determine the viability of DC servomotors. In this situation, President Inaba of Fanuc at that time adopted the management scheme in which those two basic options are to be compared and tested, as shown in Fig. 4.

How had the scheme worked? The assignment to develop an electrical pulse motor revealed that it was extremely noisy and would be difficult to be installed. Inaba immediately discarded the pulse motor and switched over to the DC servomotor. An agreement with Gettys regarding the DC servomotor was reached. Two months later, Fanuc engineers finished work on DC servomotor, and in September 1974, the company unveiled a new line of NC products equipped with the DC servomotor at the International Osaka Machine Tool Products Fair.

Based on his extensive review of the NC revolution in the United States, however, Mazzoleni (1997) once argued: the open-loop control has never been an optimal choice in the United States. Therefore, he concluded that the concept of "technology fusion" is wrong, since the feedback system does not need any fusion among different technologies. We suspect that his argument is based solely on the experiences of US machine tool industry, which, in fact, soon disappeared essentially after the NC revolution around $1980 \mathrm{~s}^{1)}$, as was vividly depicted in Fig. 2. Therefore, we would rather argue: the United States had missed the transitional experiences in the early stages of development by which NC machine tools became available all through the entire economy including the small-and medium-sized companies (Holland, 1989).

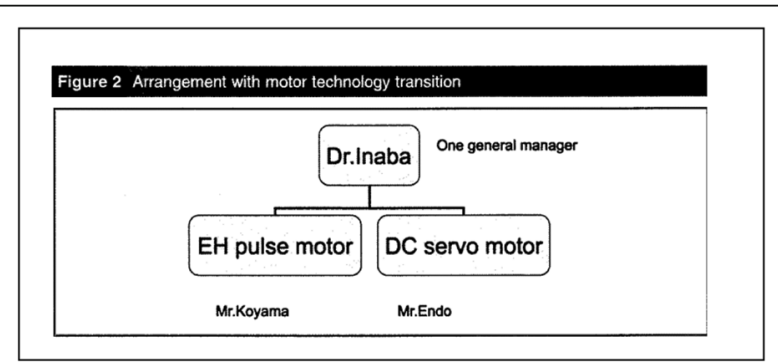

Fig. 4 Management arrangement for motor technology transition. Source: Shibata and Kodama T. (2008) 


\section{Inside-out (outbound) model}

The drastic shift also occurred in the technological landscape. The logic unit experienced a technology transition: from hard-wired logic to soft-wired logic unit based on microprocessor unit (MPU). In 1975, Fanuc possessed a stable technology and a dominant share of the NC market, based on its hard-wired NC system: the logic unit implemented with transistors, diodes, and other integrated circuits. In this system, however, at each run of the work process, a paper-tape has to be mounted into the tape-reading device. For example, 100 mountings into the reader has to be repeated in order to process 100 units of works. It is obvious, therefore, that this system is not viable since the paper tape will wear out after 100 repetitions. In contrast, the use of MPUs means that logic operations are carried out by software. Therefore, if the soft-wired NC becomes available, it would mark a significant transition.

Meanwhile, Intel was established only in 1968 as a start-up company spun off from Fairchild. At the dawn of the IC and MPU age, much uncertainty existed about its performance and reliability. Three hurdles has to be cleared before MPU could be applied to NC: performance, cost, and reliability. Especially, high reliability to withstand significant noise and temperature fluctuations in factory environments was critically important as NC is used in factories. In other words, Fanuc was not completely confident in MPU-based soft-wired NC, although Fanuc was aware of the limitations of hard-wired NC. Here again Fanuc found itself facing an intractable dilemma of having to choose between the old hard-wired NC and the new soft-wired NC.

Confronted by this impasse, Fanuc opted to pursue both technologies at the same time, as depicted in Fig. 5. A new soft-wired NC department was specifically set up to introduce MPU to NC systems. The hard-wired NC department continued to develop mass production systems. Their objective was to develop the most cost-effective and reliable hard-wired NC system possible. The soft-wired NC department focused on the latest semiconductor and MPU-related developments; how these cutting-edge technologies could be incorporated into NC systems, and whether these technologies could satisfy the reliability and performance requirements of NC systems.

With one person overseeing both departments, this made it possible to objectively weigh the relative limitations of hard-wired NC against the future potential of softwired NC. Fanuc thus created an organizational balance for transitioning to new technology by splitting into two separate departments but the command of one general manager. With this arrangement, the MPU-based soft-wired NC technology was nurtured and developed until it surpassed the hard-wired NC in performance and reliability. Once it was achieved, the hard-wired NC department and soft-wired NC

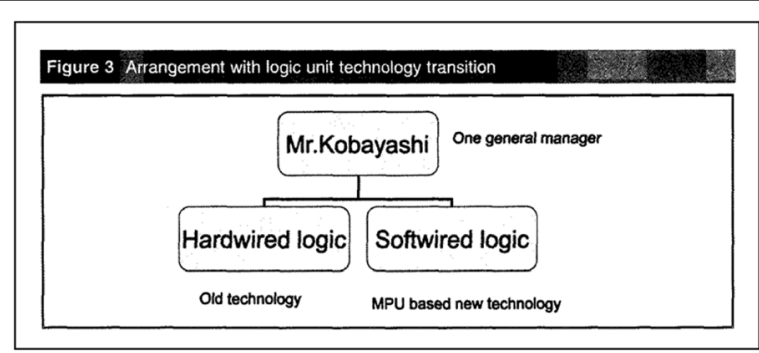

Fig. 5 Management arrangement with logic unit technology transition. Source: Shibata and Kodama T. (2008) 
department was merged. In other words, so long as Fanuc remained unsure as to which technology it would pursue, both technologies continued to coexist.

Shibata (2011) described in detail how Fanuc has built the architectural knowledge through collaboration with Intel. In 1978, Intel developed the 8086, a technologically advanced and sophisticated 16 bit MPU, the first single-chip MPU in the world that enabled customers to write their own programs. In 1979, the Fanuc system 6 series, which used the Intel 8086 16-bit MPU, was completed. To develop this advanced system 6 series, Fanuc aggressively pursued intensive collaboration with Intel to absorb and build architectural knowledge centered on Intel 8086. It was, indeed, a two-way and reciprocal collaboration between Intel and Fanuc.

It gradually became clear that the 8086 had many problems, because it used advanced semiconductor technology and was newly developed. Testing at the Intel USA site did not identify all of these defects, because it was tested in stand-alone systems. Many other defects were identified during testing by Fanuc, following installation into the system 6 series. MPU 8086 in a system 6 series NC was tested at the Fanuc site, in terms of increasing and decreasing the voltage. But Intel USA could not identify the same defects that appeared at the Fanuc site. It was sent to Intel USA due to its problems, but it was shipped back to Japan, because it had passed testing at the Intel USA site. When installed in the system 6 series, the 8086 is in complicated interdependence with other devices in the $\mathrm{NC}$ system, in contrast to the 8086 alone. For this reason, faults in the 8086 were identified only after installation in the system 6 series. The 8086 also had interface problems with other devices. Fanuc did not leave the problem solving activity only to Intel. Solving these problems required both architectural knowledge of NC systems and component knowledge of MPUs. Therefore, Fanuc and Intel had to collaborate to share each other's knowledge and experience on field. Intel USA dispatched four 8086 engineers to Fanuc, and Fanuc assigned several engineers of the system 6 series to solving these problems. At Fanuc's factory in Hino City, Tokyo, engineers of both companies worked together, repeatedly testing the 8086 every day ${ }^{2)}$.

Indeed, Fanuc went ahead and used semiconductor technology, but the technology was so new and little used at that time that even the manufacturers couldn't advise Fanuc with any certainty ${ }^{3)}$. The success of adopting the 8086 into the system 6 series made Fanuc competitive in the NC machine tool industry. Beginning in 1979, one year after the introduction of the 8086 MPU, Fanuc became its first high volume user in the world, for its system 6 series NC. Indeed, Fanuc utilized the semiconductor technology for product development more quickly than did the computer industry. In 1981, Intel developed the $8088 \mathrm{MPU}$, a partially improved version of 8086, which was used commercially for IBM-PCs. From this time on, Intel began to devote its managerial resources to the MPU business, decreasing its DRAM business. In that sense, $8086 \mathrm{MPU}$ could be called the foundation for Intel's prosperity, as well as being a turning point in Intel's history.

\section{Spiral model of innovation}

The inside-out model suggested by Chesbrough is the model enabling unused internal ideas and projects to go outside for others to use instead. However, the inside-out phenomenon of MPU from Fanuc to PC manufactures, is due to the fact that Intel improved its products in terms of reliability with close collaboration with Fanuc. Therefore, we can easily see that this inside-out mechanism differs substantially from that 
suggested by Chesbrough. In order to ascertain this difference, we show the chronology of MPU development as seen in Table 1.

A careful examination of this chronology leads us to the question about who really discovered the market for the MPU for microcomputers, i.e. who and how the demand for Intel 4004 has been articulated (Kodama and Shibata, 2015). The Japanese company for electronic calculators had the idea of designing the calculator on the basis of the general-purpose LSI (Large Scale Integration), and gave an order to Intel in 1970. Although the company which made the order, Bisicom, could not survive the severe competition of electronic calculators which followed after this order, the process of how Intel responded to this order and successfully developed MPU 4004 was well documented (Shima, 1984). In developing the 8008 MPU, Seiko Co. collaborated with Intel, in order to introduce its "programmable calculator," S-500 model. They claimed that it was the first LSI desktop computer in the world (Denda, 2000).

These cases including Fanuc's contribution to the successful development of MPU at Intel, allude to the fact that the models suggested by Chesbrough in the simple form of outside-in and inside-out phenomenon is no longer valid. It is valid only in the innovation model by final product producers such as Xerox Corporation. When it comes to the innovation by the component suppliers such as Fanuc, we have to upgrade the original model of open innovation. We can formulate the innovation process in a multi-layered innovation cycle (National Research Council, 1983) in which several players are involved along the progression of innovations. In this context, we can think of the spiral innovation model, in which the outside-in process produces the inside-out effects that entail another outside-in innovation up at an advanced level, and the process thus repeated, i.e. the spiral model of innovation (Kodama 1995).

\section{Digital convergence}

Yoffie (1996) argued that digital convergence should be defined as the unification of formerly distinct technologies into a common application domain, in which one of the antecedent technologies is already applied. This is exactly what happened to the Japanese NC machine tool industry. Even after digitization was realized, the NC machine tools had a long way to go towards digital convergence in which NC machine tools controlled by personal computers (PC) was realized.

Table 1 Chronology of mounting MPU in their product

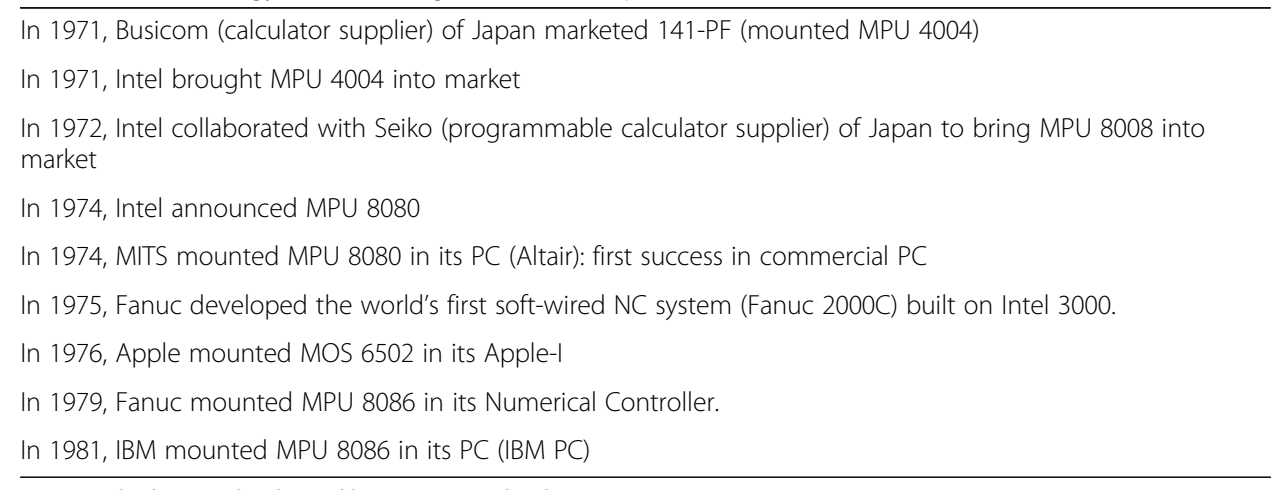


This was because NC and PC evolved independently through their own evolutionary paths (Shibata, 2009). The two systems had reached different modular architectural structures through their own evolutionary paths; the PC reached "open" architecture, while the NC reached "closed" architecture. In other words, many PC modules, such as displays, motherboards and keyboards, can be purchased separately on the open market, whereas NC modules, such as display units, control units and servo units, cannot be purchased on the open market. Therefore, it was difficult for these two systems to be integrated, although both are modular structures.

The PC controlled NC (PC-NC) was realized only after the NC system became an open architecture system in which three functions, display, calculation, and drive, were modularized and worked independently without any interferences. Under these circumstances, PC modules have been mounted to the display units in NC systems and PCs and NCs have been integrated using module dynamics, creating PC-NC. Thus, the digital convergence between NC and PC have finally materialized. Ever since 1975, when a microprocessor unit (MPU) was first incorporated into NC equipment architecture, searches have been made for appropriate module partition to accompany the latest advances in elemental technologies. As a result, NC architecture has achieved three different module partitions, as shown in Fig. 6.

After the MPU was adapted into NC equipment, efforts continued to design products with modularity, with hardware modularity achieved for the series 0 (zero) of Fanuc developed in 1985. Functions such as communications, tape storage, and automatic programming became independent hardware modules, each equipped with an MPU, with a Fanuc bus (a proprietary Fanuc common interface) used between these modules to form a linked architecture. A printed circuit board known as a hardware module was used to implement each group of function elements. In that sense, the relationship between the function and structure elements is simple. Thanks to this modularity, functions can be freely added and selected in accordance with requests from machine

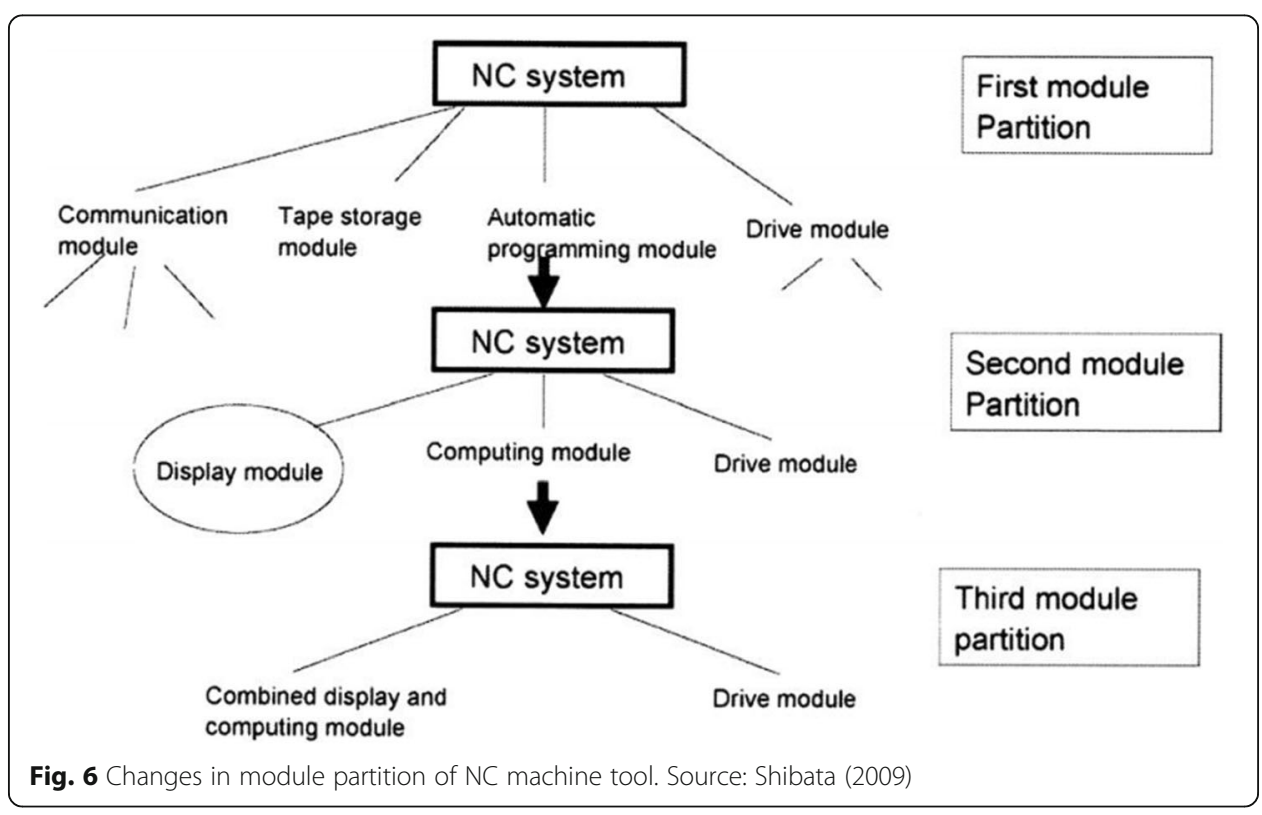


tool manufacturers. This was the first-generation NC architecture and the first module partition.

Subsequently, innovative mounting technology, using printed circuit boards in three dimensions, was adopted for NC equipment, enhancing the ability to mount electronic parts densely. This use of advanced elemental technology influenced the method of module separation and stimulated new module separation in NC equipment. As a result, NC hardware could be divided into three major modular units, display, computing, and drivers. An architecture emerged in which the units were linked with an interface based on proprietary Fanuc rules. Series 16, which employs this architecture, was released in 1991. The architecture consisted primarily of the three units of the human interface, display, computing, and drivers, physically linked by fiber-optic cables forming the Fanuc Serial Bus proprietary standard interface. This was the second-generation NC architecture and the second module partition. It is to be noted that the digital convergence of PC-NC was attained at this second module partition.

Further advances in elemental technology led to greater miniaturization. The display and computing units were combined into a single body, and an $\mathrm{NC}$ with two main units, the combined display and computing unit and the driver unit, was introduced in 1997 as Series 16i. Surface mounting and other technologies made it possible to mount NC control boards on the rear of LCD devices, combining the two into a single unit. As a result, it was possible to achieve an ultra-thin NC control board, of just $60 \mathrm{~mm}$, which reduced the space in a conventional NC unit by about one half. This was the third module partition. In this way, companies followed a repeated process of recreating module partition in order to find the optimal modularity that met advances in elemental technologies.

Now it becomes clear why the open innovation precedes the digital convergence. Through the process of open innovation, we can come more or less to the optimal module partition of a system. Only after the optimal module structure has reached, the two different digital systems can start converging. This observation leads us to the sequencing in which the digital convergence comes after the open innovation. We can thus summarize: open innovation makes the modular structure an open architecture so that the structure becomes visible for outsiders. Then, by trying all the possible combinations, we can reach a converged digital system.

By reviewing the findings made so far in this paper, especially in the sequence of proposed innovation concepts, we suggest the following sequencing based on the evidence of development of the Japanese machine tool industry since 1970s, with the authors and the publication dates in parenthesis: disruptive technology (Christensen, 1997); technology fusion (Kodama, 1992b); open innovation (Chesbrough, 2003); and digital convergence (Yoffie, 1996).

\section{Towards loT evolution}

The integration of a PC function into the display unit of an NC, indeed, made possible an NC system with flexible and enhanced PC functions such as database and networking. The database function, for example, enabled the NC operator to manage tool files; customize operation screens; and freely build human interfaces. The PC's networking 
function could also be used to operate the NC in a factory from a remote location via internet.

The combination of PC's abundant information processing with control functions, indeed, heralded innovations into a more technologically-advanced level, i.e. towards IoT evolution. IoT is defined as: a global infrastructure for the information society, enabling advanced services by interconnecting (physical and virtual) things based on existing and evolving interoperable information and communication technologies. ${ }^{4)}$ Indeed, IT revolutions are integrated and evolved into IoT innovation. Therefore, we call it as IoT evolution rather than IoT innovation.

In this context, Mori Seiki Co., Ltd., a leading Japanese machine tool manufacturer and user of $\mathrm{NC}$ controllers, developed their own PC-NC by inserting consumer PCs into the display module of their NC system, and thus enabling networking via Internet. Development began in 1997, and the MAPPS (Mori Advanced Programming Production System) was released in 2000. Mori Seiki has now completed the improved version, MAPPS III. This has enabled Mori Seiki to produce their own common specifications for operation and display methods independently of NC controllers' manufacturers, as depicted in Fig. 7.

As to the building of the global infrastructure, a cautious stance in strategic positioning is conspicuous when Japanese companies extend their business into the global landscape. This implies that priority is placed on business integration rather than on termination of unprofitable parts of business. In May 2015, M\&A (merger and acquisition) between Japanese Mori Seiki Co. and German DMG Co. (Gildenmeister Aktien Gesellschaft), was formally announced. It was reported in Germany that a "mouse" had swallowed a "cat" (Nikkei Business, 2015/5/25). Indeed, Mori Seiki (the 5th world largest machine tool company as of February 2014), acquired 52.4\% of DMG stock (the 2nd largest in the world). While DMG was established in 1870 and its total sales was 289.8 billion Japanese yen in 2014, Mori Seiki which was established only in 1948 had total sales of 117.8 billion yen. Thus, DMG-MORI SEIKI Co. became the largest company, surpassing then a No.1 Chinese Company.

It is also noted that Mori Seiki spent a rather long period of 6 years to complete this merger. In most cases of M\&A, priority is often placed on the termination of unprofitable businesses and reduction of the number of employees, rather than on business integration such as joint product development and the sharing of distribution channels. For this purpose, two specific methods were employed, which are almost opposite to the conventional wisdom and practice on M\&As. The first is to "double staffing in management," namely, two managers from each company were assigned for a same

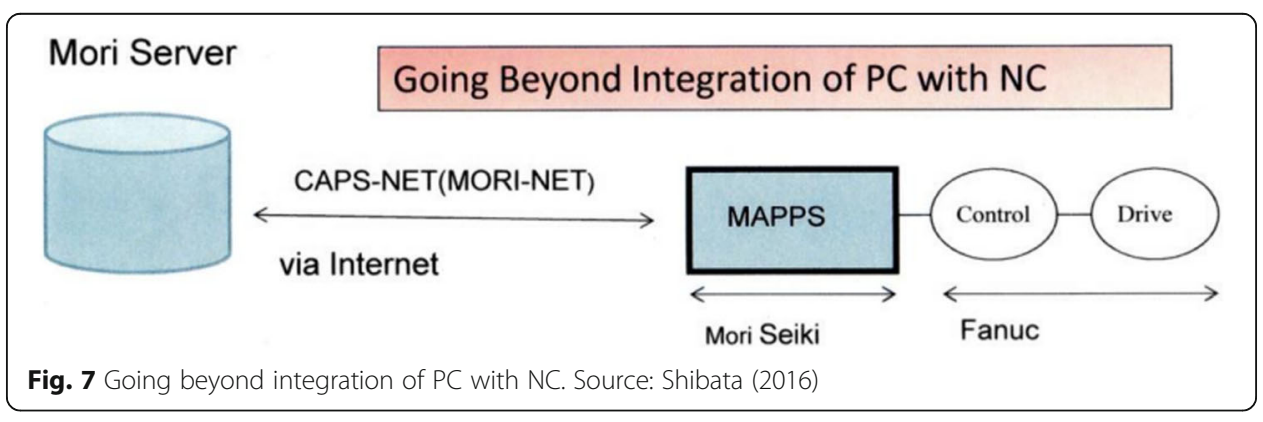


management position, because they thought, German system is better in procedures and rule-making for systems integration, while Japanese system is stronger in production scheduling and operation strategy.

The second is that enough time and budget was allocated to make possible good communication between the employees of the two companies. Their basic philosophies on the designs were different from each other. DMG's lathe uses more common parts, and thus costs less than MORI's machine, while MORI tries to accommodate every detail of the customers' demands, thus uses less common parts even in situations where cost reduction is possible. Thus they came to a common understanding among each other: there was no difference in accommodating customers' requirements, but customers' demands in Germany and Japan are indeed different from each other. In short, M\&A will not work properly unless two parties know each other well.

Having successfully undergone several transitions that occurred during 1975-2015 disruptive innovation, technology fusion, open innovation, digital convergence, and IoT evolution - Japanese production of machine tools was able to maintain its top position in the world, as far as the production of CNC (Computerized Numerical Control) machines are concerned, for a longer period spanning over more than a quarter century, as depicted in Fig. 8.

\section{Analytical framework for loT}

As the IoT innovation is deepening in contents and widening in scope, several Japanese machine tool suppliers are initiating collaboration with IT giants both in the United States and Japan. In the development of the security system, DMG-MORI SEIKI is collaborating with Microsoft of Japan. In developing the equipment to protect the factory facilities from cyber-attacks, Yamazaki Mazak Corporation is conducting a joint project with US Cisco Systems, Inc. Fanuc is developing its unique system with Cisco Systems

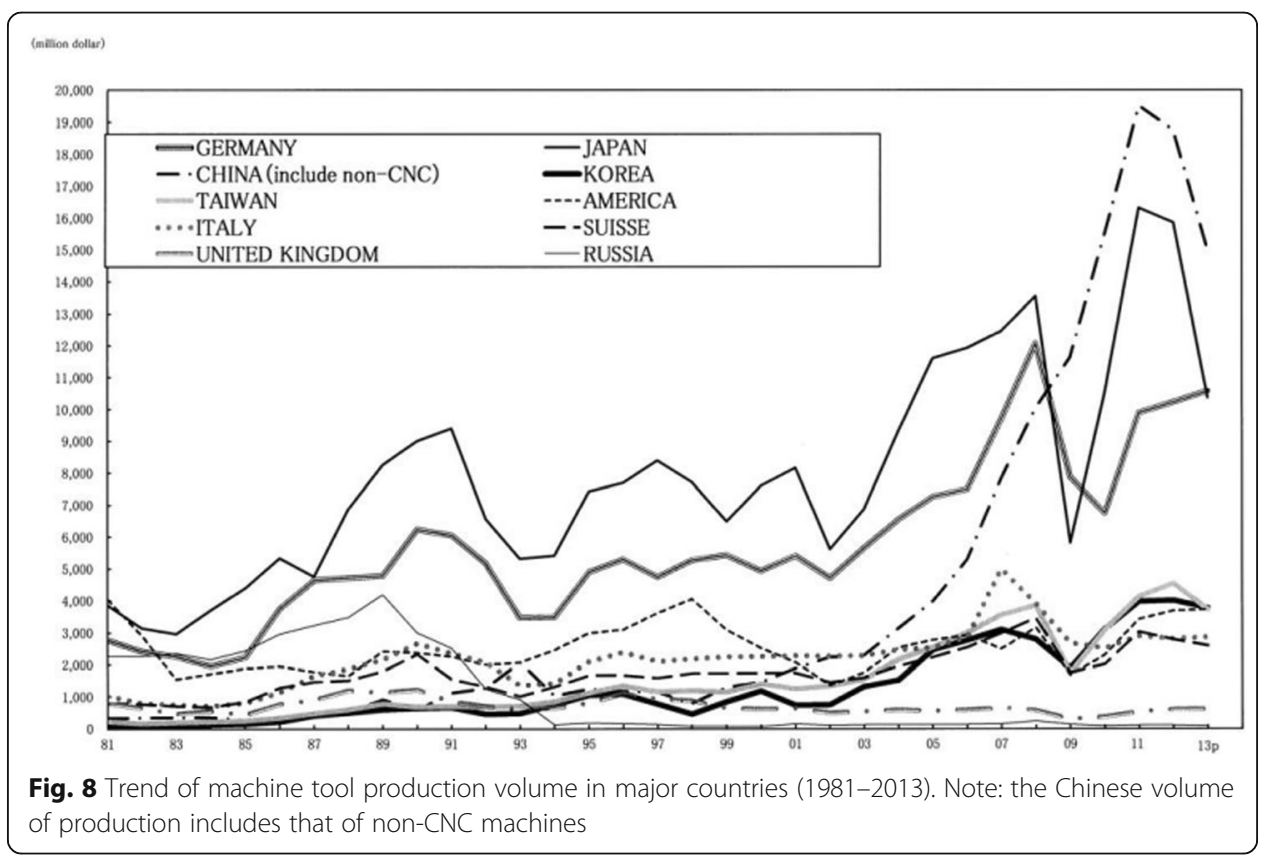


to combine IoT with AI (Artificial Intelligence). And Okuma Corporation is collaborating with Hitachi in enhancing the efficiency of factory by using IoT (Nikkei, 20,017/07/24).

On the basis of these cases described above, we observe, many Japanese machine tool suppliers are upgrading their individual systems to an advanced level, i.e. towards an IoT system. By analyzing the long-term experiences of the Japanese machine tool industry after 1970s, therefore, we attempt to develop an analytical framework within which individual IT and progressive physical technologies are built into a larger system and thus integrated into the social systems of a higher degree, i.e. theories and frameworks for IoT (Internet of Things) evolution, in contrast with those for IT (Information Technology) revolution. According to Yoffie (1996), who studied the phenomenon of "convergence" in the context of IT revolution, many companies see digital convergence delivering Joseph Schumpeter's promise of "creative destruction," and have been seeking the great new idea or grand combination that can be used to create a new digital era, sweeping away the existing order. Indeed, as is well known, Joseph A. Schumpeter in 1926, described:

Technologically as well as economically considered, to produce means to combine the things and forces within our reach. Every method of production signifies some such definite combination. In so far as the new combinations appears

discontinuously, then the phenomenon characterizing development emerges.

(Schumpeter, 1926, 1983).

In fact, Yoffie argues: the lessons of the computer revolution are that many of the greatest commercial successes were creative combinations of available technologies with new models of doing business. And he concluded: success in this new world is most likely to be fueled by companies that exploit "creative combinations" of old and new technologies. Therefore, we can say that what happened in the IT revolution confirms the Schumpeterian argument, rather than denying it.

Even before the Internet became widely available, for example, it used to be a common practice in Japan to send/receive the orders with drawings via fax machine, and to input manually the numerical data into the NC controller by means of the PC attached to the individual machine. It should be noted that this work flow is indeed a kind of creative combination of different IT technologies, and at least a new business model, i.e. new model of doing business. Therefore, it is within the concept of digital convergence as defined by Yoffie. In contrast, IoT innovation is accomplished by connecting individual components by the network with sophisticated software. However, this example of the combination of Fax-NC did realize a creative combination, but it did not yet realize connectivity which the use of Internet made possible. Therefore, we can generalize: IoT innovation is not attained by economy of scale, nor by the economy of scope, but only by the economy of connectivity, if any. We would argue, therefore, the combination of the things should be replaced by the (network) connectivity in the IoT economy.

In a relation to the concept of creative combination, Yoffie also noted: we cannot lose sight of Schumpeter's equally important insight that prior to creative destruction, entrepreneurs who have created no original means of production, will flourish by "carrying out" new combinations that take existing approaches and use them "more appropriately, 
more advantageously." In order for new combinations to be carried out successfully, indeed, Schumpeter argued:

We never assume the carrying of new combination takes place by employing means of production which happen to be unused. As a rule the new combinations must draw the necessary means of production from some old combinations.

In converging technologies, Yoffie concluded: firms are required to master a far broader array of technologies and markets, which often extend beyond their sphere of competence. One solution is to build broad-based alliance networks that try to leverage the competencies of others.

Our interpretation of this Schumpeter's important insight in the IoT contexts, meanwhile, differs a little bit from that of Yoffie in the IT context. Harvard Business School Scholars, Baldwin and Clark (2000), in this context, tried to use the computer as the powerful lens through which to observe and study the evolution of designs, and the development of an industry. They found out strikingly: the changes that can be imagined in a modular structure are spanned only by six, relatively simple modular operators. These operators can generate all the possible evolutionary paths for the structure. The six modular operators are: splitting, substituting, augmenting, excluding, inverting, and porting. The "porting" operator, as the name suggests, ports the modules to other systems. The other five operators only work within their respective system. Porting occurs when a hidden module "breaks loose"5) and is able to function (via translation) ${ }^{6}$ ) in more than one system, under different sets of design rules $^{7)}$, i.e., a different architecture.

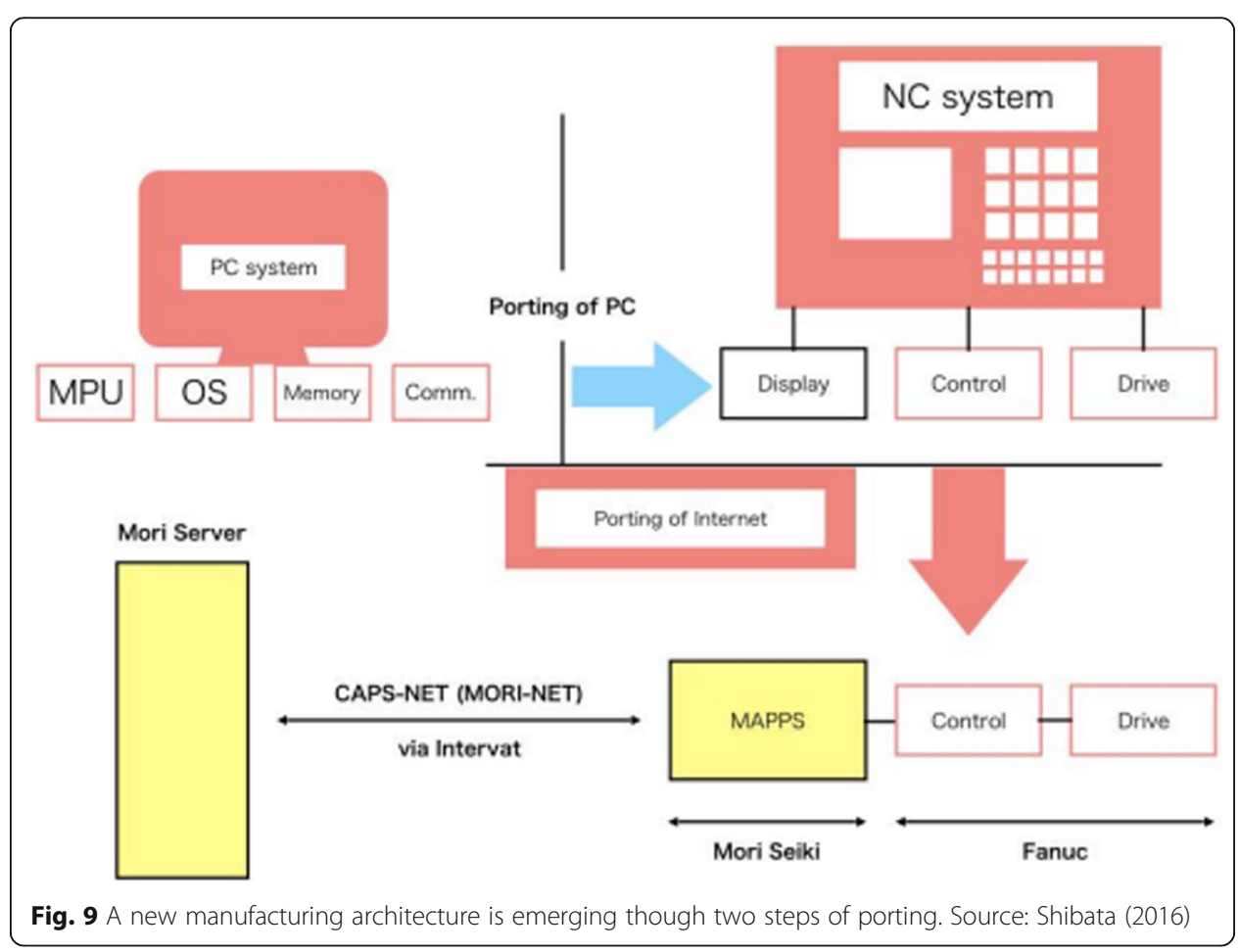


Table 2 Comparison of perspectives on innovation

\begin{tabular}{|c|c|c|c|}
\hline & Modern Technology & IT & loT \\
\hline & Joseph Schumpeter & David Yoffie & F. Kodama, et al. \\
\hline Concept: & Creative Destruction & Creative Combination & Creative Connectivity \\
\hline Carrying-out: & $\begin{array}{l}\text { Drawing from Some of old } \\
\text { Combinations }\end{array}$ & $\begin{array}{l}\text { Networking Competencies } \\
\text { of Others }\end{array}$ & $\begin{array}{l}\text { Porting of existing module } \\
\text { to new architecture }\end{array}$ \\
\hline
\end{tabular}

Based on the concept of a "porting operator," we can interpret that the IoT evolution in the machine tool industry have been realized through the two-stage process of porting: in the first stage, the PC module is ported into the NC system and, and, in the second stage, the PC-NC module is ported into the Internet system, as depicted in Fig. 9. Thus, a new manufacturing architecture is emerging whereby different factories are interconnected with each other. As indicated by this example, we argue, that "drawing the necessary means of production from some old combinations," should be replaced by "porting of a hidden module so that it can function under a different architecture."

On the basis of our arguments described above, we can summarize the comparative difference in perspectives on innovation among: Schumpeter on modern technologies; Yoffie on IT revolution; and our findings on IoT evolution, as shown in Table 2.

\section{Concluding remarks}

By referencing the monumental work by Schumpeter, we have argued that the IoT revolution combined with the development of digital economy is truly bringing about a fundamental change in technology development (Yun, 2015; Kodama, 2016). We should, therefore, attempt to reformulate innovation in a new light. For example, the IoT innovation occurring in the automobile industry, which we call "Car Renaissance," serves as a good illustration. As we witness the "true automobile" of today, indeed, we had been wandering along through the "dark ages" of the last 100 years since Ford's innovation. In conclusion, we anticipate the IoT revolution will take us into the highly sophisticated techno-society. Indeed, Techno-Renaissance is dawning upon us; it is almost here and not in the distant future as widely predicted.

\section{Endnotes}

${ }^{1}$ The top ten companies list of total sales of machine tools, shows that the Japanese manufacturers dominated in 1987 except Cincinnati Milacron of US while the US companies had dominated in the list of 1971. (Source: Heinrich, A. (2001): "The recent history of the machine tool industry and the effects of technological change" (http:// www.bwl.uni-muenchen.de/forschung/diskus_beitraege/working paper/1833.pdf).

${ }^{2}$ It was also amazing that Fanuc shared technical documents on the system 6 series with Intel engineers. These technical documents described in detail the technical specifications of system 6 series hardware and ordinarily would be kept confidential. However, Fanuc provided Intel with these technical documents to investigate the interface mechanism between the 8086 and other devices within the system 6 series. Through these intensive collaborations, they gradually overcame the technological uncertainty about MPUs and semiconductor technology. In this way, Fanuc gradually acquired MPU based new architecture knowledge and developed new communication channels and information filter within organization reflecting new architecture knowledge. 
${ }^{3}$ For example, the ICs were mounted on printed circuit boards, and they wanted to know if copper wiring was the best way to interconnect the ICs, how to reduce the noise and improve the reliability of the circuit boards, and so on. But amazingly there wasn't anyone including the vendors themselves who had sufficient experience that we could rely on their answers. They finally identified the fault and fixed it.

${ }^{4}$ http://www.itu.int/ITU-T/recommendations/rec.aspx?rec=y.2060

${ }^{5}$ The first step in porting is to modularize a module. However, to make a module portable, designers must first partition its design into (1) those parts affected by the surrounding system and (2) those not affected. They must then create a "shell" around the parameters not affected. Once the shell exists, the interior parts of the module are doubly hidden: they will not affect the surrounding system, and the system will not affect them. This "two-way invisibility" is potentially advantageous, for not only can these parts of the module be changed without changing the larger system but they can also migrate from one system to another without having to change their own inner structure. Source: Baldwin\&Clark.

${ }^{6}$ Before porting can occur, a hidden module must be modularized to have at least two submodules: one "interior" and one "exterior." The "exterior" parts of the ported module's design must then translate information from the external system into data usable by the interior sections, and vice versa. The design rules of the surrounding system and of the ported module are both equally visible to these translator modules. As their name suggests, then, translator modules are a special type of hidden module, whose role is to convert one system's information into a form usable in another system. Examples of translator modules include (1) compilers that translate high-level languages into machine instructions; (2) printer drivers that translate machine commands into printer commands; and (3) read-only-memory instruction sets that translate machine instructions into microcode. Source: Baldwin\&Clark.

${ }^{7}$ If all of these actions - sub-splitting, defining a shell, and designing translator modules - can be accomplished, the ported module will be able to function in two or more otherwise incompatible systems.

Acknowledgements

Not applicable

Funding

Not applicable

Availability of data and materials

Not applicable

Authors' contributions

Two sections (Open Innovations, Convergence) are based on previous research by TS. Both authors read and approved the final manuscript.

Ethics approval and consent to participate

Not applicable

Consent for publication

Not applicable

Competing interests

The authors declare that they have no competing interests.

Publisher's Note

Springer Nature remains neutral with regard to jurisdictional claims in published maps and institutional affiliations. 
Author details

${ }^{1}$ University of Tokyo, Tokyo, Japan. ${ }^{2}$ Graduate School of Economics and Management, Touhoku University, Sendai, Japan.

Received: 26 August 2017 Accepted: 28 October 2017

Published online: 13 November 2017

\section{References}

Chesbrough, H. (2003). Open innovation: The new imperative for creating and profiting from technology. Harvard Business School Press.

Christensen, C. (1997). The innovators' dilemma: When new technologies case great firms to fail. Harvard Business School Press.

Christensen, C. (2003). The Innovator's solution: Creating and sustaining successful growth. Harvard Business School Press.

Christensen, C., \& Rosenbloom, R. (1995). Explaining the attacker's advantage: Technological paradigms, organizational dynamics, and the value network. Research Policy, 24, 233-257.

Cupertino Silicon Valley Press @2011 (ed.): His Own Words and Wisdom (Steve Jobs Biography) Remarkable Quotations by Steve Jobs.

Denda, N. (2000): When Intel was yet Small (in Japanese), https://www.amazon.co.jp/dp/4526045047/

Holland, M. (1989). When the machine stopped. Harvard Business School Press.

Kodama, F. (1986a). Technology fusion as a new pattern of innovation and its analysis (in Japanese). Bull Japanese Soc Mech Eng, 89(80), 44-49.

Kodama, F. (1986b). Inter-disciplinary research: Japanese innovation in mechatronics technology. Science and Public Policy, 13(1), 44-51.

Kodama, F. (1992a). Japan's unique capability to innovate: technology fusion and its international implications. In T.

Arrison, C. Bergsten, E. Graham, \& M. S. Harris (Eds.), Japan's Growing Technological Capability: Implications for the U.

S. Economy (pp. 149-164). Washington D.C: National Academy Press.

Kodama, F. (1992b). Technology fusion and the new R\&D. Harvard Business Review, 70(4), 72-75.

Kodama, F. (1995). Emerging patterns of innovation: Sources of Japan's technological edge. Boston: Harvard Business School Press.

Kodama, F. (2016): "Dynamic Complexity of loT Innovation Process: Japanese Experiences," speech at Conference on Finance and Innovation by Asian Development Bank Institute, December 8th, Tokyo.

Kodama, F. (2017). Changes in modes of technological learning, in Managing Convergence in Innovation. In L. Kong-rae (Ed.). Routledge.

Kodama, F. and Shibata, T. (2015): Demand articulation in the open-innovation paradigm, Journal of Open Innovation: Technology, Market, and Complexity, 1:2, SpringerOpen Journal, 1-21.

Lee, G. (2008). Relevance of organizational capabilities and its dynamics: What to learn from entrants' product portfolios about the determinants of entry timing. Strateg Manage J, 29, 1257-1280.

Lee Kong-rae, ed., (2017): Managing convergence in innovation: The new paradigm of technological innovation, Routledge.

Mazzoleni, R. (1997). Learning and path-dependence in the diffusion of innovations: Comparative evidence on numerically controlled machine tools. Research Policy, 26, 405-428.

National Research Council. (1983). International Competition in Advanced Technology: Decision for America (pp. 28-38). (Washington D.C.: National Academy Press)

Rosenberg, N. (1976). Perspectives on Technology. Cambridge University Press, pp. 15-18.

Shibata, T. (2009). Product innovation through module dynamics. J Eng Technol Manage, 26, 46-56.

Shibata, T. (2011). Managing the change of architecture knowledge. Int J Innov Manage, 15(5), 1093-1112.

Shibata, T. (2016): "IoT and innovation," (in Japanese), Newscom, 27: 4-13.

Shibata, T., \& Kodama, M. (2008). Managing technological transition from old to new technology: Case of Fanuc's successful transition. Business Strategy Series, 9(4), 157-162.

Shima, M. (1984). How the Microcomputer was born: behind the development of Intel 4004 (in Japanese). Iwanami Publisher. Yoffie, D. (1996): "Competing in the age of digital convergence," California Management Review, 38: 31-53.

Yun, J. (2015): "How do we conquer the growth limits of capitalism? Schumpeterian dynamics of open innovation," Journal of Open Innovation: Technology, Market, and Complexity, 1:17, 1-20.

\section{Submit your manuscript to a SpringerOpen ${ }^{\circ}$} journal and benefit from:

- Convenient online submission

- Rigorous peer review

- Open access: articles freely available online

- High visibility within the field

- Retaining the copyright to your article

Submit your next manuscript at $>$ springeropen.com 